\title{
The Effect of Exogenous Melatonin on Kiwifruit antioxidant system under low light environment
}

\author{
Dong Liang ${ }^{1,2, a, \#, \text { Yanqiu Shen }}{ }^{1, b, \#}$, Qin Wang ${ }^{1, c}$ Hui Xia ${ }^{1,2, d^{*}}$ \\ 1 College of Horticulture, Sichuan Agricultural University, Chengdu, Sichuan, China; \\ 2 Institute of Pomology and Olericulture, Sichuan Agricultural University, Chengdu, Sichuan, \\ China;

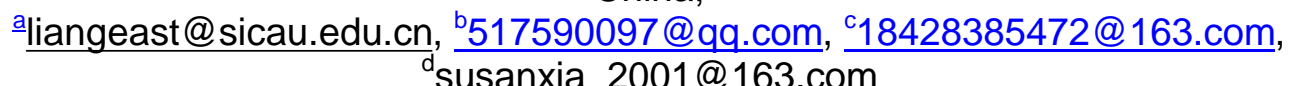 \\ ${ }^{\#}$ Co-first author, ${ }^{*}$ Corresponding author
}

\section{Keywords: Melatonin, Kiwifruit, Low light, Antioxidant system}

\begin{abstract}
Melatonin (N-acetyl-5-methoxytryptamine) in plants is to act as an antioxidant providing protection against environmental agents. In our study, we used different concentration of melatonin (control, $50 \mu \mathrm{M}, 100 \mu \mathrm{M}$ and $200 \mu \mathrm{M}$ ) to investigate the effect of melatonin on antioxidant system under low light. The results suggested melatonin has strong antioxidant ability to effectively scavenge $\mathrm{H}_{2} \mathrm{O}_{2}$ and reduce relative electrical conductivity (REC). The $100 \mu \mathrm{M}$ and $200 \mu \mathrm{M}$ group had a significant effect. Moreover, melatonin also activated peroxidase (POD), superoxide dismutase (SOD), and catalase (CAT) compared to control group. In general, $200 \mu \mathrm{M}$ melatonin had the mostly significant effect on protecting antioxidant system.
\end{abstract}

\section{Introduction}

In agricultural production, many biological or abiotic factors accelerate leaf senescence, such as low light conditions[1, 2]. However, stress-induced leaf senescence has also been associated with increased generation of reactive oxygen species (ROS) [3]. Excessive ROS will destroy the integrity of membrane structure. As a result, the relative conductivity of the leaves increased. In plants, the cells suppress the ROS accumulation by activating the enzymatic antioxidant pathway, including POD, SOD, CAT, and suppress the stress-induced senescence accordingly.

Melatonin was first detected in edible plants in 1995, and the physiological function of which in plants have been widely studied [4]. A fundamental function attributed to melatonin is to act as an antioxidant in plants. Some research suggested that melatonin regulating the redox state of cells, decreasing ROS and maintaining cell membrane stability [5].

Our study investigated the effect of different concentration of melatonin on antioxidant system by determine the $\mathrm{H}_{2} \mathrm{O}_{2}$, REC and antioxidant enzymes ability. The results will provide a crucial proof in the application of melatonin in oxidation and anti-low light in the field.

\section{Treatment and Methods}

Treatment. We used the healthy and uniform kiwifruit seedlings to assign two conditions for pretreatment: (i) standard water supply and low light (control), (ii) solution of $50 \mu \mathrm{mol} \cdot \mathrm{L}^{-1}$ melatonin in water and low light $\left(50 \mu \mathrm{M}\right.$ group), (iii) solution of $100 \mu \mathrm{mol} \cdot \mathrm{L}^{-1}$ melatonin in water and low light (10 $\mu \mathrm{M}$ group), (iv) solution of $200 \mu \mathrm{mol} \cdot \mathrm{L}^{-1}$ melatonin in water and low light (200 $\mu \mathrm{M}$ group). The pretreatment was conducted for 8 days in an open experimental field. During this period, the seedlings were treated with melatonin or water every 2 day by root irrigation $(20 \mathrm{~mL}$ per pot). After the fifth irrigation, the seedlings were put under shade with $60 \%$ sunlight (the day was 
set as 0 days). The plants were sampled at day $0,2,4,6,8$ between 10:00 and 11:00 h, by removing the fifth to ninth leaves upward along the stem from three trees per treatment. Every treatment used 15 pots, 3 seedlings per pot. The samples were quickly frozen after collection and stored in a cryogenic refrigerator at $-80^{\circ} \mathrm{C}$ for subsequent index determination. All reactions were performed by using the leaf mixture of three kiwifruit seedlings with three technical and three biological replicates.

Determination of $\mathrm{H}_{2} \mathrm{O}_{2}$, REC and antioxidant enzymes. Determination of $\mathrm{H}_{2} \mathrm{O}_{2}$ concentration was based on the method of Lin et at.[6] and the measurement of REC referred to Chen et al.[7] The activities of POD, SOD, CAT were determined using the method of Wang and Huang [8].

\section{Results}

Exogenous melatonin scavenged $\mathrm{H}_{2} \mathrm{O}_{2}$ and reduced relative conductivity. When plants are under stress, cells are induced to produce and accumulate ROS. In our treatment, the control group accumulated the highest content under low light, about $368.81 \mu \mathrm{mol} . \mathrm{g}^{-1} \mathrm{FW}$ (FW: fresh weight), while the content of melatonin application groups ( $50 \mu \mathrm{M}$ group, $100 \mu \mathrm{M}$ group and $200 \mu \mathrm{M}$ group) were significantly lower than control group. However, there was also markedly difference between each concentration. The lowest $\mathrm{H}_{2} \mathrm{O}_{2}$ content was detected in $100 \mu \mathrm{M}$ group $\left(51.15 \mu \mathrm{mol} . \mathrm{g}^{-1} \mathrm{FW}\right)$, and the content of $50 \mu \mathrm{M}$ group and $200 \mu \mathrm{M}$ group were higher than $100 \mu \mathrm{M}$ group (222.69 $\mu \mathrm{mol} . \mathrm{g}^{-1}$ and $102.71 \mu \mathrm{mol} . \mathrm{g}^{-1}$ respectively). Besides, we measured the REC. The results suggested $50 \mu \mathrm{M}$ melatonin had no difference compared to control group, both of which had higher REC (56.32\% and $54.59 \%$ respectively), while the $100 \mu \mathrm{M}$ and $200 \mu \mathrm{M}$ group had significant effect on the reduce of REC, about $25.7 \%$ and $23.9 \%$ respectively lower than control group.
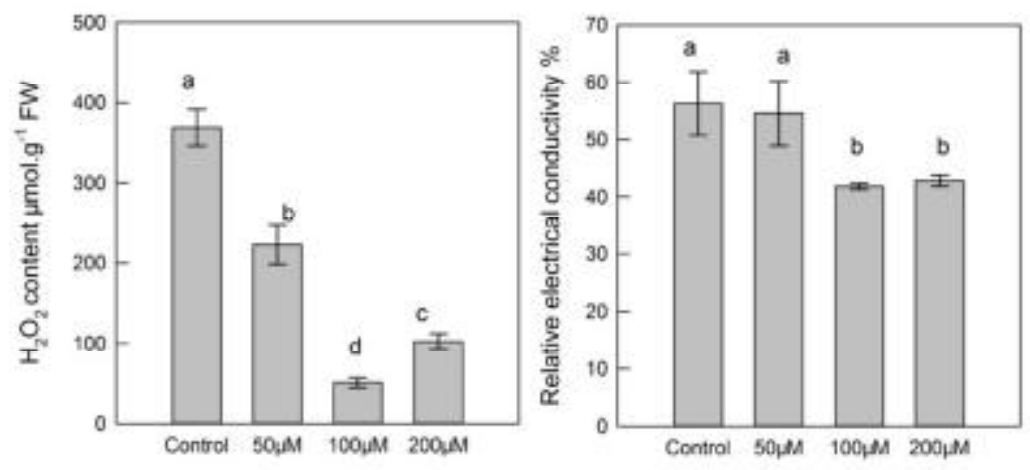

Figure 1.Effect of exogenous melatonin on $\mathrm{H}_{2} \mathrm{O}_{2}$ and REC under weak light. FW means fresh weight (the same as below). Data are show as means $\pm \mathrm{SE}(\mathrm{n}=9)$, different letters indicate significant differences at $p<0.05$ level.

Exogenous Melatonin improved the activity of antioxidant enzymes. In plants, the antioxidant enzymes system alleviated the damage of peroxides to the membrane system. However, after melatonin pretreatment, the activity of all the enzymes were markedly in control group lower than melatonin pretreatment groups (50 $\mu \mathrm{M}$ group, $100 \mu \mathrm{M}$ group and $200 \mu \mathrm{M}$ group). Regarding POD, $200 \mu \mathrm{M}$ group had highest activity and 91.7\% higher than control group, $100 \mu \mathrm{M}$ group followed (51.6\% higher than control group), and $50 \mu \mathrm{M}$ group had lowest activity compared with $100 \mu \mathrm{M}$ and $200 \mu \mathrm{M}$ group. For SOD, just the group of $100 \mu \mathrm{M}$ and $200 \mu \mathrm{M}$ induced the increase of sod activity, but there was no difference between $100 \mu \mathrm{M}$ and $200 \mu \mathrm{M}$ group. For CAT, the activity of all the groups enhanced, but the just $50 \mu \mathrm{M}$ and $200 \mu \mathrm{M}$ group had significant difference with control group (15.3\% and $20.2 \%$ respectively higher than control group). 

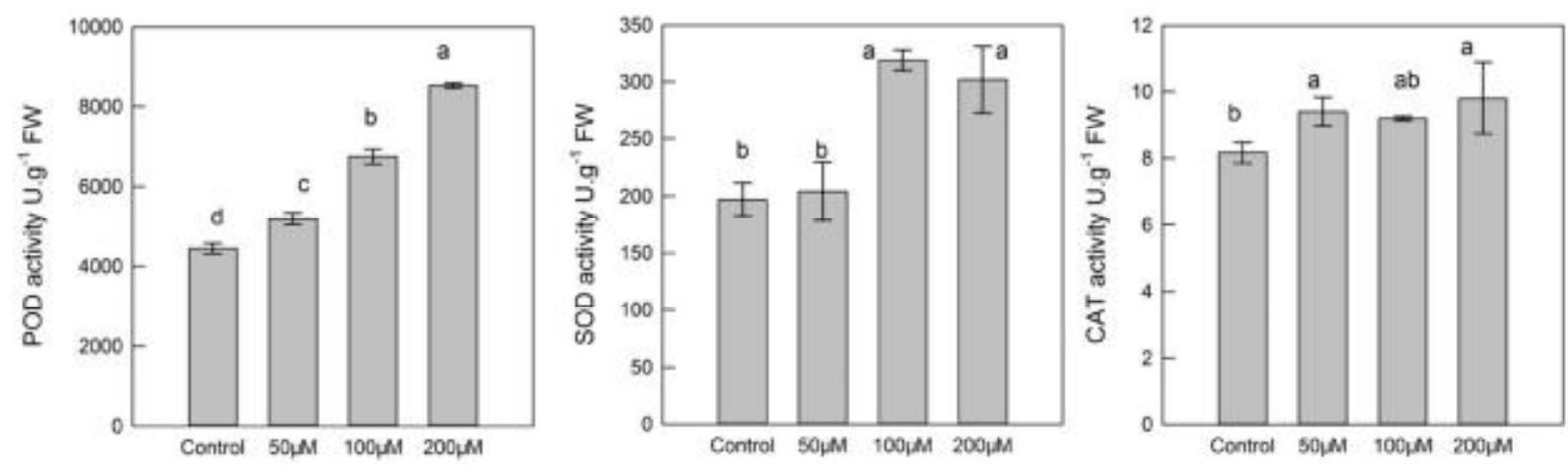

Figure 2.Effect of exogenous melatonin on antioxidant enzymes under weak light. Data are show as means $\pm \mathrm{SE}(\mathrm{n}=9)$, different letters indicate significant differences at $p<0.05$ level.

\section{Discussion}

Stress-induced leaf senescence will generate excessive reactive oxygen species. Excessive reactive oxygen species will accelerate the membrane lipid oxidation, and destroy the integrity of membrane structure. Thus, senescence is characterized by loss of membrane integrity, which is generally considered as increased electrolyte leakage and result the increase of REC [9]. In our study, the content of melatonin application groups was significantly lower than control group attributing to the antioxidant ability of melatonin. Besides, The $100 \mu \mathrm{M}$ group had the mostly significant effect on scavenge $\mathrm{H}_{2} \mathrm{O}_{2}$, and the $200 \mu \mathrm{M}$ group followed. Due to the lower content of $\mathrm{H}_{2} \mathrm{O}_{2}$ in $100 \mu \mathrm{M}$ group and $200 \mu \mathrm{M}$ group, the REC of which were also markedly lower than control group. The beneficial effect of melatonin on scavenging hydrogen peroxide and protecting cell membrane stability also monitored in Malus hupehensis[10].

Moreover, we detected that melatonin also activated the antioxidant enzymes and the ability of three enzymes was enormously enhanced than control group. Maybe, it is because that melatonin induced the relative expression levels of antioxidant enzyme related genes [11]. Additionally, the $200 \mu \mathrm{M}$ group had the marked effect on inducing the increase of POD ability, but regarding SOD, the $100 \mu \mathrm{M}$ group was no difference with $200 \mu \mathrm{M}$ group, and the three groups also have no difference in CAT. Due to the higher enzymes activity, the lower concentration of $\mathrm{H}_{2} \mathrm{O}_{2}$ and REC also can be explained.

\section{Conclusions}

In our study, melatonin significantly activated the enzymes POD, SOD and CAT and acted as an efficient antioxidant, $\mathrm{H}_{2} \mathrm{O}_{2}$ was efficiently scavenged, thus, membrane integrity was maintained. After comprehensive analysis of all results, we suggest $200 \mu \mathrm{M}$ melatonin had the mostly significant effect on protecting antioxidant system. It is hoped that our results will lay a foundation for the application of melatonin.

\section{Acknowledgements}

This work was financially supported by the Sichuan Technical Supports Foundation (2016NZ0105), Training Programs of Innovation for Undergraduates in Sichuan (201610626057). 


\section{References}

[1] Humbertof, C.; Irman, R.; Maríav, C.; Susanam, G.; Lilianab, P.; Maríadelcarmen, R.; Atilioj, B. Changes in hydrogen peroxide homeostasis and cytokinin levels contribute to the regulation of shade-induced senescence in wheat leaves: Plant Sci Vol.177 (2009), p. 698-704

[2] Brouwer, B.; Ziolkowska, A.; Bagard, M.; Keech, O.; Gardeström, P. The impact of light intensity on shade-induced leaf senescence: Plant Cell Environ Vol.35 (2012), p. 1084-1098

[3] Wang, P.; Yin, L. H.; Liang, D.; Li, C.; Ma, F. W.; Yue, Z. Y. Delayed senescence of apple leaves by exogenous melatonin treatment: toward regulating the ascorbate-glutathione cycle: J. Pineal Res Vol.53 (2012), p. 11-20

[4] Dubbels, R.; Reiter, R. J.; Klenke, E.; Goebel, A.; Schnakenberg, E.; Ehlers, C.; Schiwara, H. W.; Schloot, W. Melatonin in edible plants identified by radioimmunoassay and by high performance liquid chromatography-mass spectrometry: J. Pineal Res Vol.18 (1995), p. 28-31

[5] Fischer, T. W.; Kleszczyński, K.; Hardkop, L. H.; Kruse, N.; Zillikens, D. Melatonin enhances antioxidative enzyme gene expression (CAT, GPx, SOD), prevents their UVR induced depletion, and protects against the formation of DNA damage ( 8 - hydroxy - 2' deoxyguanosine) in ex vivo human skin: J. Pineal Res Vol.54 (2013), p. 303-312

[6] Lin, Z. F.; Li, S. S.; Lin, G. Z.; Guo, J. Y. Relationship between $\mathrm{H}_{2} \mathrm{O}_{2}$ accumulation and membrane lipid peroxidation in senescent leaves and chloroplasts: J. Plant Physiol Mol Biol (1988), p. 16-22

[7] Chen, A.; Han, R.; Li, D.; Lin, L.; Luo, H.; Tang, S. A Comparison of Two Methods for Electrical Conductivity about Plant Leaves: Journal of Guangdong Education Institute Vol.30 (2010), p. 88-91

[8] Wang, X. K.; Huang, J. L., Principles and techniques of Plant Physiology and Biochemistry experiments. Higher Education Press (HEP) Beijing, China, 2015.

[9] Rolny, N.; Costa, L.; Carrión, C.; Guiamet, J. J. Is the electrolyte leakage assay an unequivocal test of membrane deterioration during leaf senescence?: Plant Physio Bioch Vol.49 (2011), p. 1220

[10] Li, C.; Wang, P.; Wei, Z. W.; Liang, D.; Liu, C. H.; Yin, L. H.; Jia, D. F.; Fu, M. Y.; Ma, F. W. The mitigation effects of exogenous melatonin on salinity-induced stress in Malus hupehensis: J. Pineal Res Vol.53 (2012), p. 298-306

[11] Zhang, J.; Li, H.; Xu, B.; Li, J.; Huang, B. Exogenous Melatonin Suppresses Dark-Induced Leaf Senescence by Activating the Superoxide Dismutase-Catalase Antioxidant Pathway and Down-Regulating Chlorophyll Degradation in Excised Leaves of Perennial Ryegrass (Lolium perenne L.): Front. Plant Sci. Vol.7 (2016), p. 